\title{
Female genital cutting among the Somali of Kenya and management of its complications
}

Jaldesa Guyo

Ian Askew

Population Council

Carolyne Njue

Monica Wanjiru

Population Council

Follow this and additional works at: https://knowledgecommons.popcouncil.org/departments_sbsr-rh

Part of the Demography, Population, and Ecology Commons, Family, Life Course, and Society Commons, Gender and Sexuality Commons, International Public Health Commons, Maternal and Child Health Commons, Sociology of Culture Commons, and the Women's Health Commons How does access to this work benefit you? Let us know!

\section{Recommended Citation}

Jaldesa, Guyo, Ian Askew, Carolyne Njue, and Monica Wanjiru. 2005. "Female genital cutting among the Somali of Kenya and management of its complications," FRONTIERS Final Report. Washington, DC:

Population Council. 


\title{
Female Genital Cutting among the Somali of Kenya and Management of its Complications
}

\author{
Guyo W. Jaldesa \\ Ian Askew \\ Carolyne Njue \\ Monica Wanjiru
}

February 2005

This study was funded by the UNITED STATES AGENCY FOR INTERNATIONAL DEVELOPMENT (USAID) under the terms of Cooperative Agreement Number HRN-A-0098-00012-00 and In-house Project Number 8016 53083. The opinions expressed herein are those of the authors and do not necessarily reflect the views of USAID. 


\section{Acknowledgements}

The authors would like to acknowledge and thank USAID's Special Initiative for FGC for their financial contribution and unequivocal support.

The authors would also like to acknowledge several individuals for their important roles in the study, particularly Dr. Bashir Mohamed, the District Medical Officer of Health, Mandera and Mr. Hussein Nur, the Public Health Officer, Mandera, who were study team leaders for Mandera and Wajir, and Fardhosa Ali, team leader for the Eastleigh area of Nairobi.

We are deeply grateful to everyone who participated in the study. Special thanks also go to Ms. Habiba of Habiba International, who played a great role of mobilizing the community influentials and who made arrangements for the interviews, to Hassan Mohamed and Mohamed Ibrahim who were the rapporteurs during the study, and to all the research assistants for their dedication and commitment.

This study was an extraordinary learning experience, and the participation of the community members, health providers and other community influentials, whose views and experiences, which form the core of this report, is acknowledged with much appreciation. Their views and experiences have greatly helped in the formulation of recommendations for feasible and effective interventions. 


\section{Executive summary}

The Somali community living in Kenya (and in their native Somalia) has practised the severest form of female genital cutting (FGC), infibulation, for centuries. To understand the context within which the practice takes place, and how its complications are managed, the Population Council's Frontiers in Reproductive Health Program (FRONTIERS) undertook a diagnostic study in North Eastern Province (Wajir and Mandera districts) and in the Eastleigh area of Nairobi. The study collected data through: in-depth interviews and focus group discussions with community and religious leaders, and recently married and unmarried men and women; interviews with health providers, and an assessment of their clinics' readiness to offer safe motherhood and FGC-related services; and interviews with antenatal clients who had been cut.

The study confirmed that FGC is a deeply rooted and widely supported cultural practice. Several closely related reasons are used to sustain the practice: religious obligation, family honour, and virginity as a prerequisite for marriage; an aesthetic preference for infibulated genitalia was also mentioned. However, FGC plays no role as a rite of passage. Underlying these reasons are the use of infibulation to enforce the cultural value of sexual purity in females. A relevant lesson learned from FGC abandonment strategies elsewhere is the importance of working with intermarrying groups, as FGC is a critical prerequisite for marriage. If consensus can be generated that marrying uncut women is acceptable within the social group and this decision is then publicised through a formal declaration, then a "social convention shift" can happen. Thus, when developing a strategy for working with community members, it is important to determine marriage patterns and to organize activities accordingly.

The study also found that the health sector is ill equipped to serve women who have been cut, particularly infibulated pregnant women. However, this stems from an overall weakness in the availability and quality of safe motherhood services in North Eastern Province. In addition, and especially in Nairobi, health workers are increasingly being approached to perform infibulations and re-infibulations.

Specific recommendations were made about the ways in which the health system could strengthen its handling of FGC among the Somali. Policy makers should seek to improve management of associated complications within the framework of improving safe motherhood generally, and contribute to abandonment efforts through ensuring that staff adhere to $\mathrm{MOH}$ policy, and become involved in community-level discussions to create a climate for behaviour change.

Given the clear strength of feeling that FGC is a critical component of Somali culture, efforts to encourage behaviour change cannot focus solely on education about health and rights alone. The underlying reasons for the practice need to be discussed and debated so that a desire for change can emanate from the community itself. Because of the Somali community's perception that efforts to abandon FGC are driven by international interests, working with them will require credible organisations and individuals that have gained their trust and acceptance. 


\section{Table of Contents}

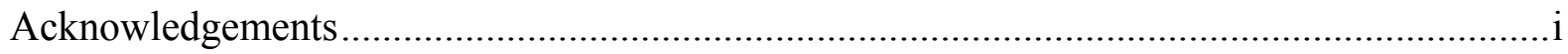

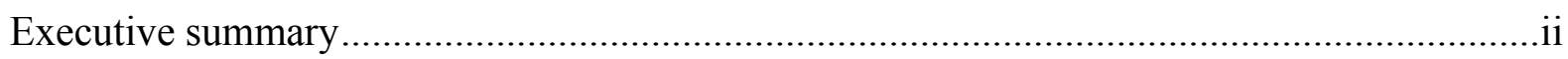

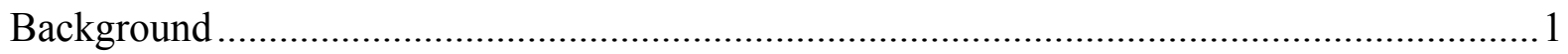

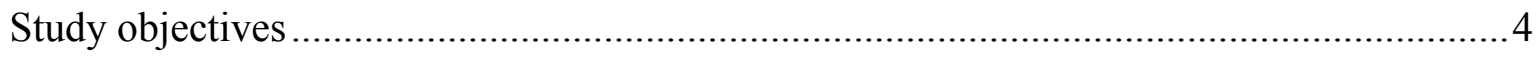

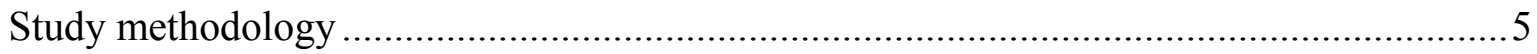

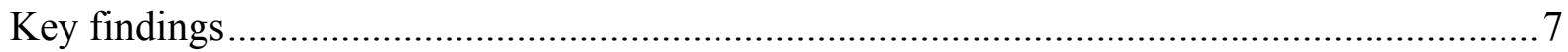

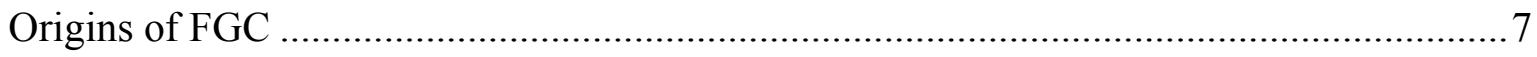

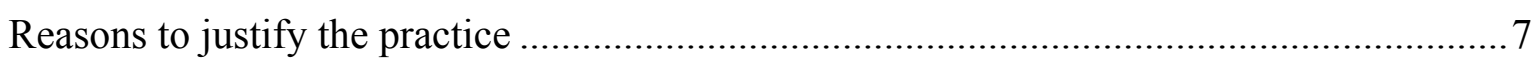

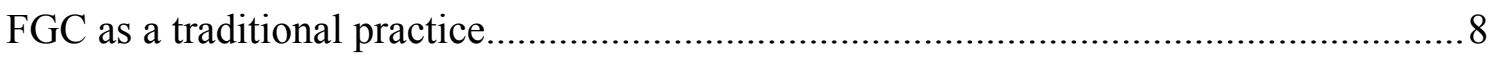

FGC and marriage - preservation of virginity and suppression of sexual desire ……......8

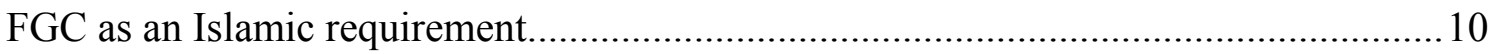

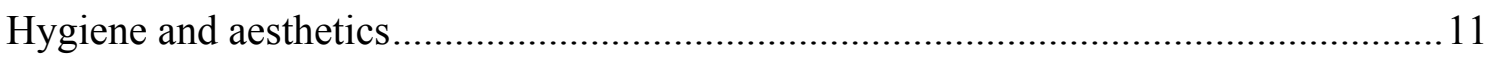

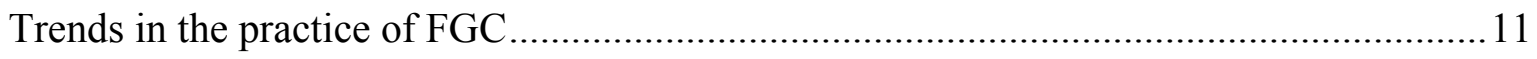

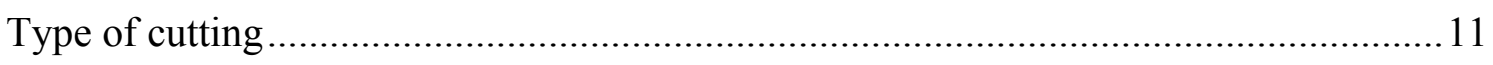

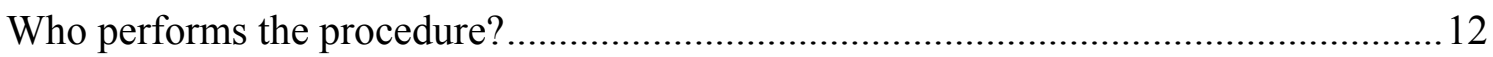

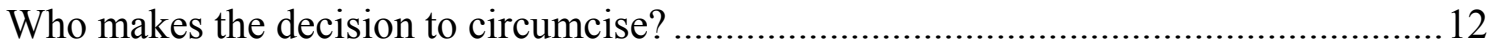

How is the procedure undertaken?............................................................................. 12

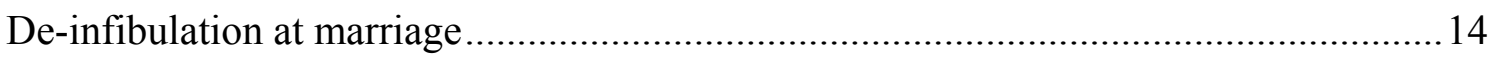

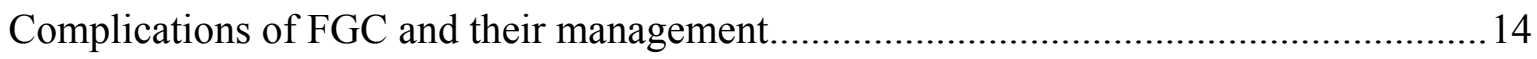

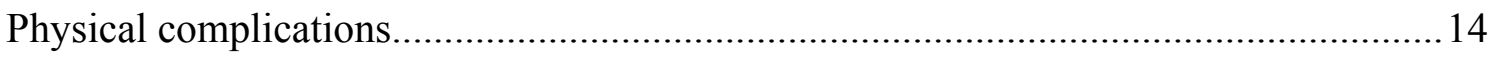

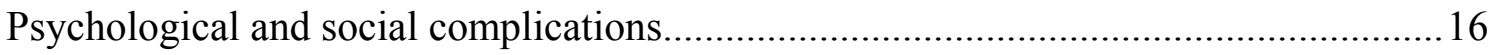

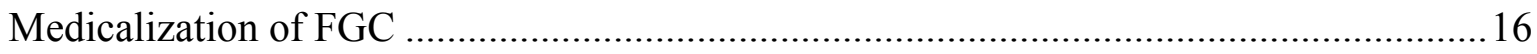

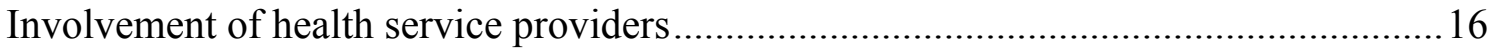

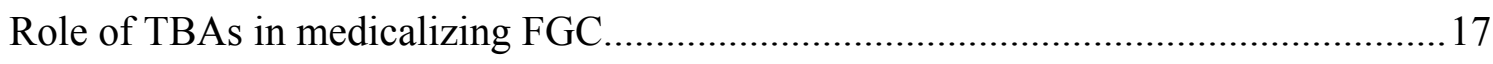

Antenatal care and birth planning for infibulated women ................................................ 17

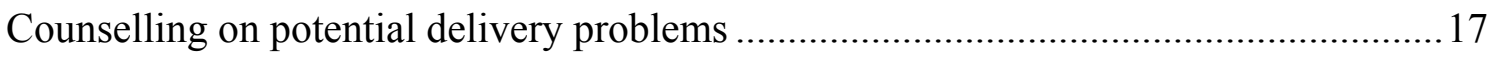

Re-infibulation after delivery............................................................................ 18

Health facilities' preparedness to handle FGC complications ...........................................18

Awareness of FGC as a violation of human, legal and sexual rights .................................19

Is FGC seen to violate a woman's human rights?.........................................................19

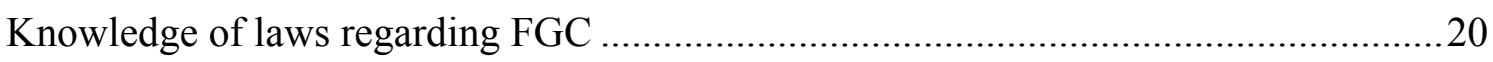




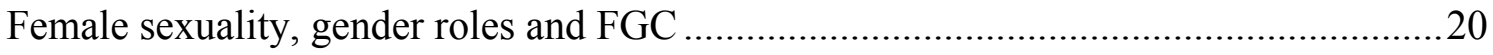

Developing an appropriate FGC abandonment strategy ..........................................21

Religious leaders........................................................... 21

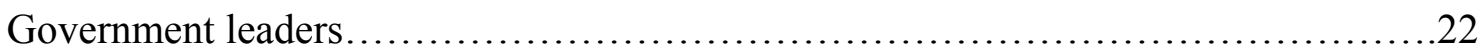

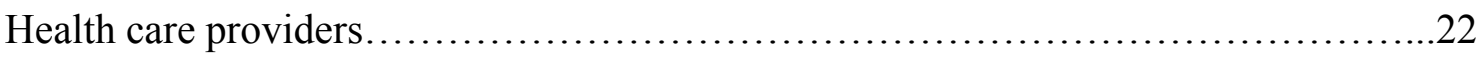

Traditional FGC providers................................................23

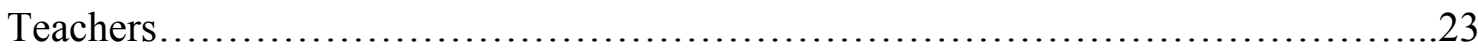

Married women and men........................................................ 3

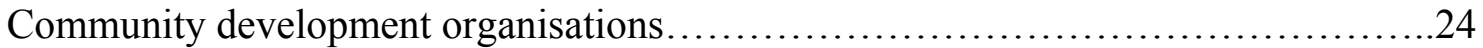

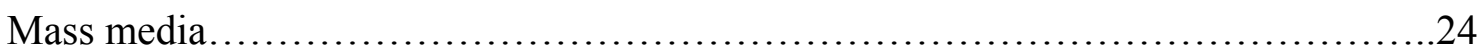

Strengthening health services to manage complications............................25

Conclusions and recommendations....................................... 27 


\section{Background}

Female genital cutting (FGC), also known as female genital mutilation (FGM) and female circumcision, is practiced in 28 countries of sub-Saharan Africa, a few countries in the Middle East and Asia, and among immigrant populations from these countries in Europe, North America and Australasia. As many as 100-140 million girls and women worldwide have undergone the practice, and at least two million girls are at risk of being cut each year, about 6,000 girls a day.

FGC refers to the intentional removal of part or all of the external genitalia, or other damage to the female genitalia, for cultural or other non-therapeutic purposes. ${ }^{1} \mathrm{WHO}$ recognises four types of FGC, the most severe of which is type III (sometimes known as Pharaonic circumcision ${ }^{2}$ or infibulation). Approximately 15 percent of all genital cutting is of this type. ${ }^{3}$ Type III consists of the removal of all, or part of, the clitoris, excision of all, or part of, the labia minora, and cutting of the labia majora to create raw surfaces, which are then stitched or held together so that the scar tissue forms a cover over the vagina when healed. Thorns or stitches may be used to hold the two sides of the labia majora together, and the legs may be bound together for up to 40 days. A small opening is left to allow urine and menstrual blood to escape. ${ }^{4}$ The Somali ethnic community, both in the country of Somalia and those living in Kenya, has practised genital cutting for centuries and the practice appears to have remained largely unchanged. The 2003 Kenya Demographic and Health Survey (KDHS $)^{5}$ found a prevalence of 96.8 percent among Somali respondents and 98.9 percent for the North Eastern Province where the majority live. Type III predominates, although type II is also prevalent.

Those advocating against the practice have paid much attention to the physical complications that can be associated with FGC, but until recently, there has been little systematic analysis of this association. The popular literature abounds with graphic generalisations and anecdotes of girls and women suffering severe gynaecological and obstetric complications and morbidities, including death. As noted by Obermeyer ${ }^{6}$ however, these data tend to be based on case history reports from hospitals, ${ }^{7}$ there are no comparisons with uncut women to judge their relative frequency, and most reports are from populations practising the most severe form, infibulation. A few studies have been carried out that analyse this relationship through large sample sizes, comparisons with uncut women, and between women with different types of cut, by

1 WHO. 1998. "Female Genital Mutilation: An Overview," Geneva: WHO.

2 This term is used as this form of genital cutting is thought to have been introduced by the Pharaohs of Egypt.

WHO. 1996. "Female Genital Mutilation: Report of a Technical Working Group,” Geneva: WHO.

WHO. 1995. “Classification and Definitions of Female Genital Cutting,” Geneva: WHO.

Central Bureau of Statistics (CBS) [Kenya], Ministry of Health (MOH) [Kenya], and ORC Macro. 2004. Kenya Demographic and Health Survey 2003. Calverton, Maryland: CBS, MOH, and ORC Macro.

Obermeyer, C. 1999. "Female genital surgeries: The known, the unknown, and the unknowable," Medical Anthropology Quarterly, 13(1): 79-106.

7 See, for example, many of the studies reported in WHO. 2000. "A Systematic Review of the Health Complications of FGM including Sequelae in Childbirth," Geneva: WHO. 
differentiating between gynaecological, obstetrical, and perinatal complications, and by controlling for factors such as socio-demographic characteristics.

In a study among women attending clinics for reproductive health services and who had undergone different types of FGC, five percent of women in Mali and 14 percent in Burkina Faso $^{8}$ had an observable physical complication that could be associated with FGC, most frequently keloids, haemorrhage, and vaginal narrowing due to scarring. A positive relationship was found between the type of cut a woman has undergone and the likelihood that she will have a visible long-term complication, although no major differences were found between the type of complication and the type of cut, in that all types of complications were more prevalent among women with type II and type III cuts than among those with a type I cut. The study also found that uncut women were significantly less likely to have an observed complication or require an additional procedure (e.g., episiotomy, caesarean section) during delivery than were women who had been cut. Moreover, the likelihood of experiencing a difficulty during delivery increased with the severity of cutting.

A community-based study in the Gambia ${ }^{9}$ among women who had type I or II cutting found, however, that commonly cited physical complications, such as damage to the perineum or anus, vulval tumours, and keloids, as well as painful sex, infertility, and prolapse were no more common in cut than in uncut women. The study did find increased likelihood of bacterial vaginosis and herpes simplex virus 2 , which may suggest that cut women are at increased risk of acquiring HIV. A study of obstetric outcomes at first delivery among women having type I and II cuts in Nigeria ${ }^{10}$ found that, after controlling for social factors, place of delivery, and assistance at delivery, cut women were no more likely than uncut women to report a complication or to have needed an additional medical procedure.

In short, these studies highlight the importance of differentiating between the types of cutting experienced (notably type III) when considering physical complications, as women with type I and II cuts are usually no more likely that uncut women to suffer gynaecological and obstetric complications. More data are needed from a variety of settings, however, thus the forthcoming results from a WHO-coordinated study among 28,393 women attending 28 obstetric units in six countries are eagerly awaited.

Comparative studies that have included women with type III cutting (as is practised by the majority of Somali in Kenya) do confirm that physical complications can be serious among such women and are more prevalent than among uncut women. For example, evidence from Norway shows that perinatal complications (e.g. foetal distress, emergency caesarean sections, low Apgar scores and pre-labour deaths) were two to three times more frequent among Somali migrants

8 Jones H., N. Diop, I. Askew, and I. Kaboré. 1999. "Female genital cutting practices in Burkina Faso and Mali and their negative health outcomes," Studies in Family Planning, 30(3): 219-230.

9 Morison, L., C., Scherf, G. Ekpo, K. Paine, B. West, R. Coleman, and G. Walraven. 2001. "The long-term reproductive health consequences of female genital cutting in rural Gambia: A community-based survey," Tropical Medicine and International Health, 6(7):1-11.

$10 \quad$ Slanger, T., R. Snow, and F. Okonofua. 2002. "The impact of female genital cutting on first delivery in Southwest Nigeria," Studies in Family Planning, 33(2): 173-184. 
than among ethnic Norwegians. ${ }^{11}$ A study comparing Sudanese immigrants with ethnic Saudi Arabian women also found significantly higher levels of prolonged second stage of labour, neonatal distress and postpartum haemorrhage. ${ }^{12}$

Within Kenya, a much higher level of maternal mortality (17/1000 births) was found among Somali women delivering in the Provincial General Hospital at Garissa in the North Eastern Province compared with women delivering in Machakos $(0.45 / 1000)$ and Nairobi $(0.56 / 1000),{ }^{13}$ where women are more able to access safe motherhood services and where relatively fewer women are cut, or are cut less severely. Whether this is because of their infibulated status or because of poorer access to safe motherhood services, is an important consideration, however. A comparison between Somali women living in North Eastern Province with those living in Nairobi, where access to quality safe motherhood services is much higher, would help to address this issue.

Slanger et al. and Vangen et al. highlight the importance of considering the health-seeking behaviour and conditions under which women experience labour and delivery when considering whether poor obstetric outcomes can be attributed directly to infibulation. For example, a study of the reasons for perinatal deaths among circumcised immigrants from Ethiopia, Eritrea, and Somalia in Sweden ${ }^{14}$ concluded that none of these deaths were directly due to the woman's circumcised status, but were caused by malformations, poor health-seeking behaviours, or suboptimal care, a finding supported by research among Somali women and local health workers in Norway. ${ }^{15}$

There is an intuitive expectation that genital cutting adversely affects a woman's sexuality, in terms of desire and sensation. Indeed, for many cultures, including the Somali, FGC is practised largely because of the belief that it is a mechanism for reducing a woman's sexual feelings. Conversely, the reduction in a woman's sexuality through FGC has been one of the key messages used by advocates against the practice, as it is seen as contravening a basic human right.

Again, there is very little scientific evidence that addresses this issue, and especially research that compares cut with uncut women. A consensus is building through emerging research that women who have been cut do experience sexual desires and feelings, although the physical mechanisms

11 Vangen S., C. Stoltenberg, R. Johansen, J. Sundby, and B. Stray-Pedersen. 2002. "Perinatal complication among ethnic Somalis in Norway," Acta Obstetricia et Gynecologica Scandinavica, 81:317-22.

12 De Silva, S. 1989. “Obstetric sequelae of female circumcision,” European Journal of Obstetrics, Gynaecology and Reproductive Biology, 32: 233-40.

13 Jaldesa, G., Z. Qureshi, S. Kigondu, and S. Wanjala. 1998. "Maternal morbidity and mortality at Garissa Provincial Hospital: 3-year retrospective survey," Journal of Obstetrics and Gynaecology of East and Central Africa, 14(2): 68-71.

Essén, B., B. Bödker, N. Sjöberg, S. Gudmundsson, P. Östegen, and J. Langhoff-Roos. 2002. "Is there an association between female circumcision and perinatal death?" Bulletin of the World Health Organization, 80: 629-632.

15 Vangen, S., R. Johansen, J. Sundby, B. Træen, and B. Stray-Pedersen. 204. "Qualitative study of perinatal experiences among Somali women and local healthcare professionals in Norway," European Journal of Obstetrics \& Gynecology and Reproductive Biology, 112: 29-35. 
for sexual stimulation may be different than for women with an intact clitoris and labia. ${ }^{16}$ The extent to which this affects desire and pleasure is unclear. For example, a study in Nigeria comparing women with type I and II cuts with uncut women found no significant differences in frequency of intercourse, in arousal or in orgasm. ${ }^{17}$ For infibulated women, however, there is greater tissue removal and a reduced vaginal opening that makes penetration difficult and painful. Interviews with infibulated women and with men in Sudan indicate ways in which couples adapt their sexual behaviours to allow for this, ${ }^{18}$ but these and other studies ${ }^{19}$ give conflicting findings as to whether desire and satisfaction are diminished or not.

Given the global condemnation of the practice as a violation of several basic human rights, its association with health, psychological, and sexual complications, and the fact that it is now illegal in Kenya, the Population Council's FRONTIERS Program, at the request of USAID/Kenya, conducted this study to better understand the Somali community's perceptions and practice of FGC, to ascertain ways in which the community might be encouraged to abandon the practice, and to identify how the health system could be more actively engaged in managing complications and in discouraging the practice. ${ }^{20}$

\section{Study objectives}

1. To document the reasons currently used by the Somali community to justify continuation of FGC.

2. To document Somalis' perceptions of women's and children's rights in relation to bodily integrity, gender relations, and sexuality.

3. To identify key actors who influence the decision to sustain the practice at the community level.

4. To understand how behavioural norms are sustained generally within the Somali community.

See presentations made at the recent International Research Seminar on Advancing Knowledge on PsychoSexual Effects of FGCM/C: Assessing the Evidence organized by the International Network to Analyze, Communicate and Transform the Campaign Against FGM/C (INTACT) in Alexandria, Egypt, October 1012, 2004. Website:

http://www.intact-network.net/main2/document/articles/abstracts.htm.

Okonofua, F., U. Larsen, F. Oronsaye, R. Snow, and T. Slanger. 2002. "The association between female genital cutting and correlates of sexual and gynaecological morbidity in Edo State, Nigeria," British Journal of Obstetrics and Gynaecology, 109(10): 1089-96.

Lightfoot-Klein H. 1989. "The sexual experience and marital adjustment of genitally circumcised and infibulated females in the Sudan," Journal of Sex Research, 26(3): 375-392; Almroth L., V. AlmrothBerffren, O. Hassanein, S. Al-Said, S. Hasan, U-B. Lithell, and S. Bergstrom. 2001. "Male Complications of Female Genital Mutilation,” Social Sciences and Medicine, 53: 1455-1460; Gruenbaum, E. 2004. "Sexual response and Sudanese conceptions of the infibulated and uninfibulated vulva: research in Sudan, 2004,"Paper presented at the Seminar on Advancing Knowledge on Psycho-Sexual Effects of FGCM/C: Assessing the Evidence. Cairo: INTACT. Psychosexual Impact," Journal of Sexual Marital Therapy, 27(2): 465-473.

This study was undertaken as part of a collaborative effort with UNICEF/Kenya (funded through the Development Cooperation Office of the Italian Government), which implemented a similar study in Garissa District of North Eastern Province and Moyale District of North Eastern Province. 
5. To identify those within the community who have openly abandoned the practice and understand their motivation to do so and how the decision was taken.

6. To identify community-based organizations or individuals with which partnerships could be established to support community-based FGC abandonment interventions.

7. To assess whether Somalis living in Nairobi have different beliefs, attitudes and behaviours concerning FGC than those living in North Eastern Province.

8. To document the readiness of selected clinics and their staff to offer essential and emergency obstetric care, and to manage gynaecological complications associated with infibulation.

9. To document the role, if any, of medical staff in carrying out infibulation and de-infibulation.

\section{Study methodology}

This diagnostic study was undertaken in two of the larger towns in North Eastern Province, Wajir and Mandera, and among the Somali community living in the Eastleigh area of Nairobi. Data collection and sampling was organised as follows:

a) In-depth interviews were conducted in all three sites with influential people in the community, including religious leaders, political and opinion leaders, teachers and women's group leaders; eighteen interviews were undertaken in North Eastern Province and 11 in Nairobi. Unfortunately, in the time available for the study, it proved impossible to identify anyone who would admit having abandoned FGC, such is the universality of the practice, thus no interviews were possible with this sub-group.

b) Focus group discussions (FGDs) were conducted in Mandera and Eastleigh with representatives of the following population sub-groups, each of which could present different perspectives on the issues: recently married men and women, unmarried men and women, older men and women, religious leaders, and FGC practitioners. Eight FGDs were held in Mandera, with one FGD for each sub-group, and six FGDs were held in Nairobi. ${ }^{21}$ In both sites, FGDs comprised of between three to six respondents. Verbal permission to interview anyone under the age of 18 years, and all unmarried females regardless of age, was sought from their parents or guardian beforehand.

c) Facility Assessment: The quality of existing safe motherhood services (i.e. antenatal, delivery, and postpartum services) and the capacity of health facilities and staff to manage FGC-related complications were assessed in selected clinics within the study sites using an adaptation of the Rapid Assessment Tool that has been developed by the Population Council and used elsewhere in Kenya. This tool includes an inventory of the clinic equipment, supplies and functions, and in-depth interviews with staff about their experience and skills.

All health facilities and staff that offer these services in the study sites were included: Two health centres, three hospitals, and three dispensaries from Mandera and Wajir, and six private nursing homes in Eastleigh. The only government facility in Eastleigh 
(Pumwani Maternity Hospital) was having administrative problems at the time of fieldwork thus data could not be collected.

d) Interviews were conducted with all the staff responsible for safe motherhood services in these facilities to evaluate their knowledge and practice of FGC and how its complications are handled. Eighteen health providers were interviewed from North Eastern Province and 26 from Nairobi.

e) Exit interviews were conducted with all antenatal clients attending the clinics during the field visits -49 clients in Nairobi and 52 from North Eastern. These women were interviewed about their personal experience with FGC, including the circumstances under which they underwent the procedure, experiences encountered during circumcision, after onset of menses, at first coitus, and during delivery. They were also asked about any birth planning information concerning their infibulated condition given during the antenatal consultation, including information about re-infibulation.

f) Discussions with organisations conducting anti-FGC activities: All organizations implementing FGC abandonment activities in the study sites were identified through discussions with local leaders. Interviews were held with the appropriate person in each organization to create a listing and brief description of the organisation's activities and to gather lessons about what may or may not work in this setting to encourage abandonment of the practice. 


\section{Key findings}

\section{Origins of FGC}

Although the Somali have practised FGC for a long time, none of the respondents interviewed could explain, with any degree of certainty, the origins of the practice. This lack of clarity supports findings from other research undertaken among this population. ${ }^{22}$ Oral tales were cited that trace the practice to Egyptian traders who brought it to Northern Somalia, from where it spread to the rest of the region. Infibulation was thought to have been started by a legendary woman ruler in Northern Somalia, Arawelo, who was known to castrate men and sew up women to suppress their sexual desire as a form of punishment. It is not clear, however, how such an oppressive act would be adopted and converted into a strongly celebrated cultural practice. Some elderly men indicated that infibulation could have been started to safeguard family honour, and girls' pride and dignity by preserving virginity. It was also not clear whether men or women initiated it.

\section{Reasons to justify the practice}

Several reasons were used to justify continuation of FGC by the Somali: a cultural tradition that brings honour for the family and girl; a means for controlling female sexuality; a perceived requirement of Islam; a necessary condition for marriage; and genital beauty and cleanliness. The relative importance attached to these reasons by health providers and by ANC clients intending to cut their daughters is illustrated in Table 1 (the question was asked slightly differently for each group, as is reflected in the response categories, although multiple responses were possible for both).

Table 1: Reasons for FGC according to health care providers and ANC clients (frequency)

\begin{tabular}{|c|c|c|c|}
\hline Reasons & $\begin{array}{l}\text { Health providers } \\
\qquad \mathrm{N}=44\end{array}$ & Reasons & $\begin{array}{c}\text { ANC clients } \\
\quad \mathbf{N}=55\end{array}$ \\
\hline Tradition & 38 & Religious tradition & 21 \\
\hline Prevent immorality & 28 & Avoid discrimination & 15 \\
\hline Suppress female sexual desire & 26 & Respect for the mother & 11 \\
\hline Preserve virginity & 21 & Better marriage prospects & 5 \\
\hline Better marriage prospects & 18 & Avoid promiscuity & 4 \\
\hline Family honour & 18 & Maintain virginity & 2 \\
\hline Cleanliness & 15 & Circumcision is 'good' & 1 \\
\hline Confer respect to girls & 14 & Mother was circumcised & 1 \\
\hline Removal of dirty genitalia & 12 & Girls have to bleed & 1 \\
\hline Religious demand & 11 & & \\
\hline Husband's sexual pleasure & 2 & & \\
\hline
\end{tabular}
region, Kenya; Jaldesa G., Z. Qureshi, C. Kigondu , and S. Wanjala. 1998. "Factors enhancing the practice of FGM among the Kenyan Somalis," Journal of Obstetrics and Gynaecology, East and Central Africa, 14(2): 110-114. 


\section{FGC as a traditional practice}

The reason most commonly given was that FGC is considered a long-standing traditional practice of the Somali culture that has never been questioned. A family risks losing respect within the community and becoming outcasts if it fails to circumcise its daughters, thus circumcision is one way of maintaining the family honour. According to an FGC practitioner from Mandera, "If the girls are not circumcised, [they] will bring shame to [their] mother and also to [their] relatives. A lady whose daughter is not circumcised is pointed [at] by others."

Some of the respondents believe that circumcision confers respect on the family thus is linked with the value of the dowry the family would get when the daughter gets married. A refund could be demanded if the girl has not been stitched to the satisfaction of the husband's family.

Some respondents argued that mothers circumcised their daughters because they too had been circumcised: "I was cut so I must cut her so that she feels what I felt." (ANC client, Nairobi) Another client, asked if she would like to circumcise her daughter, said she would "because it is the way that I have been done to me, my mother and grandmother, so we should follow the culture the way it is." (ANC client, Nairobi)

Peer pressure was thought to contribute to girls agreeing to circumcision, in order to avoid ridicule by their age mates. Peers were said to refer to an uncircumcised girl as the "outcast, the uncircumcised one, non-believer, the open one." (Female teacher, Mandera) According to female respondents, girls sometimes challenge each other to physically show that they had been circumcised, in order to be respected in a group. Over 60 percent of the antenatal clients said that they had been scared before their circumcision, while one-quarter reported feeling happy and looked forward to it. After being cut, however, three-quarters said that they had felt proud, while the remainder could not explain their feelings or felt unhappy.

\section{FGC and marriage - preservation of virginity and suppression of sexual desire}

Virginity at marriage is extremely highly valued in Somali culture, and the second most common group of reasons centred around the belief that infibulation is the most valid means for ensuring that a girl will remain a virgin until marriage, and that proof of an intact infibulation on the wedding night is proof of her virginity. Participants at an FGD of older men in Nairobi compared girls who are not virgins to "a bottle of soda that was opened before it is ready for consumption."

Immediately before the marriage day, girls are checked physically and an intact, stitched vaginal orifice is considered proof of virginity.

They practice it to safeguard the virginity and avoid shame later when the lady is married. Families used to be abused as a result of this. It has happened in some instances that after a wonderful wedding once a man realises that a lady is not circumcised, that following morning the man left and divorced the lady. The stitching is done due to fear from men, just to satisfy the men who do not trust women. (Mandera District Women's leader)

According to one traditional practitioner, "Traditionally this practice was adopted to prove to the man who will marry this girl that she has not been used by any other man before him."

Others stated that "The Somali culture wants the girls to be virgins. If the girls had Sunna type of circumcision, the virginity can break by itself. That is what worries people because we have seen 
men who if they find the girl has not been stitched leave her in the morning and say how will I ever believe her again. They will only believe she was a virgin if she was stitched." (Recently married women FGD, Nairobi)

A married couple are expected to have sexual intercourse on their wedding night. On the following morning, the bridal bedclothes are checked for bleeding; if it is found, the women ululate and announce that the girl was virgin. The girl's mother is feted and rewarded for having taken good care of her daughter.

Unmarried girls may also be subjected to regular checks to ensure that the vaginal opening remains a specific, recommended size; if it is larger, the girl is re-stitched. "The mother does frequent checks to the daughter to ensure that she has not had intercourse with a man. If she is suspected to have had intercourse with a man or the mother realises that her daughter is not a virgin anymore she will be punished and re-stitched. Then she will be strictly monitored." (FGD of older men, North Eastern Province)

Cutting and stitching is thought to suppress female sexual desire and expression; the Somali believe that an infibulated woman will not want to have premarital or extramarital sex because she will not have a strong sexual drive. A traditional practitioner argued that an uncircumcised woman "will start chasing men because of her uncontrollable sexual urge, excessive sexual desire, she will be very vulnerable, she has no security and [will] subsequently [be] disgraced. Circumcised girls will not go for another man because her husband will trust her." (Traditional practitioner FGD respondent, North Eastern Province)

Uncircumcised women, conversely, were thought to be easily aroused, and to possess strong sexual desires, which is not culturally acceptable. According to some of the elders interviewed, it is only men who are expected to enjoy sexual intercourse. "The one who is not circumcised, if they make love, she will still want more, because the clitoris is there and she has a lot of sexual desires." (Elderly women's FGD, Nairobi) Unmarried young men from Mandera held similar views: "... especially when the lady is circumcised and you plead for that thing, it will take you time to get it, but the one with a clitoris, she has been provoked, there is high chance she does the sex."

According to a respondent in an FGD of unmarried men from Mandera, girls are stitched to make sex before marriage difficult "... this lady has been stitched, and the act is going to be very painful...Because of the pain, she wishes not to go for sex before she is married."

Respondents in an FGD of newly married women in Nairobi felt that girls are circumcised so that they will not have sexual urges, and they thought that men did not want women to enjoy sex: "They don't want the mothers to enjoy and they don't know pleasure themselves, they want a girl who is finished, with nothing." Another respondent added, "If she stays with the husband she is ok, and if she stays without it is ok, she does not feel like she is missing something." And because they don't enjoy sex, the "husbands marry and marry many women." But a respondent among the recently married women from Mandera thought differently concerning infibulation. She said that it was done "... so that the birth canal or the opening becomes small and the man should not think of any other woman except you."

The belief was widespread that a Somali man would not marry a woman who is not circumcised because "If the girl is not circumcised, however beautiful she is, she is not wanted by men. He wants or prefers the stitched one, who [he] will be happily busy with through the night. But he 
will not be happy with the open one. I will do whatever will make them like my daughter, I will stitch her up tight" (Elderly men FGD, Nairobi)

\section{FGC as an Islamic requirement}

A third group of reasons given was that $\mathrm{FGC}$ is a requirement of the Islamic religion, and consequently that uncircumcised girls are regarded as non-Muslims. "The fear is that the men would consider such women as non-believers. So they must undergo the cut and be stitched to Islamise them. Actually most women would not talk of circumcising but only Islamise their daughters as though the lady was a pagan. So that is the reason." (FGC practitioner, Mandera) However, all the religious leaders interviewed in the study shared a common opinion - that infibulation (type III or Pharaonic circumcision) is not permitted under Islam, and that any woman who had been infibulated could, in theory, claim for compensation from the circumcisers. They do not support infibulation because, "The Pharaonic circumcision which Somalis practice is not there in the Quran and the Sunna of the Prophet. The way the Somalis do it is very bad and this results in a lot of problems. It is a culture which is very far from the way Islam said, it is like slaughtering someone which can be compensated if people demand for compensation." (Religious leader, Mandera)

Some religious leaders (and other respondents) believed, however, that female circumcision is a Sunna practice in Islam, that is, was recommended by the Prophet Mohammed. "We can not be told to stop the Sunna type because it is in our religion, so even if the government says we stop, we cannot stop it. And then the girls also they had their own age mates who have been circumcised and they are not, they will pressurise their mothers to do that to them." (Opinion leader, North Eastern)

Their views were divided on what exactly constituted a Sunna circumcision, that is, how much tissue should be cut. According to some Islamic scholars interviewed in Nairobi, both men and women are regarded in Islam to have equal rights to enjoy sex, thus excising the clitoris itself is not allowed. Although there was no consensus among these scholars, those who support FGC said that for a woman to be 'pure' (in the religious sense), the prepuce covering the clitoris is the only part that should be cut, arguing that its removal actually increases female sexual pleasure and satisfies the husband. "That part reflects on the face of the woman... brightens her face and add beauty." (Religious leader, Nairobi)

According to Islamic scholars in Nairobi, FGC is an optional rather than obligatory Sunna behaviour: "So if women are circumcised according to Islam, well and good, and if they are not, well and good." (Religious scholar, Nairobi) By contrast, male circumcision is seen an obligatory Sunna behaviour that was mentioned by the Prophet as one of the seven things a man must do to remain pure. "Under the pureness of men and things which religion performs ... scholars say circumcision is highly stressed for men but for women [it] is optional." (Religious scholar, Nairobi)

Religious scholars saw circumcision as an act of religious purification, that is, something that has to be done to allow an individual to perform religious rituals, including prayers. "Whoever is not circumcised, we term them as a non-believer, somebody who is not circumcised cannot slaughter an animal. The person cannot perform prayers." (FGC practitioner, Mandera)

The prayers of an uncircumcised person (male or female) are considered unacceptable, and other Muslims cannot eat any animals that he/she slaughters. The clitoris (kintir, yuub, or baji) is 
considered haraam (dirty, not pure in the sense of religious purity and cleanliness) thus it must be removed. To illustrate the seriousness with which religious purity is regarded, a recent case was cited in Mandera of an infibulated girl who, having died from bleeding within the vagina, could not have Islamic prayers offered on her behalf because blood had been trapped inside her infibulated vagina, thereby rendering her impure. "There are issues causing a lot of problems to this community, for one, the problem of girls [having] complications in their bodies and others having problems in performing religious teachings like prayers due to blockage during menstruation." (Religious leader, North Eastern Province)

\section{Hygiene and aesthetics}

Several respondents expressed the belief that a woman's external genitalia can harbour dirt and germs, thus for them to be cleaned they need to be removed. A belief commonly expressed was that uncircumcised women are never clean. "Those who are not circumcised are dirty, and they will always produce a foul smell, so we are circumcised to be kept clean." (Newly married women FGD, Mandera) Physical cleanliness is also closely linked with religious purification as discussed above.

Discussions with older women revealed deep-seated beliefs that the female genitalia in their natural form are ugly and that infibulation makes them presentable and beautiful. One respondent stated, "I will circumcise my daughter because I don't want people to say that my girl is empty, I want her to be beautiful and her thing [to be] shiny like a mirror." A female teacher from Mandera said that, "you know, this clitoris grows with the body of the girl. They don't want to see that thing, it will look abnormal, and it becomes ugly." A similar view was held by the old men from Mandera "If she grows up, so will the clitoris. The clitoris will become hard so that the knife will not be able to cut it." Similar perceptions have been expressed among infibulated women in Sudan. ${ }^{23}$

\section{Trends in the practice of FGC}

\section{Type of cutting}

Of the 44 health workers interviewed, two-thirds (29) felt that there had been a gradual decline in the proportion of girls undergoing FGC, and a similar proportion felt that the severity of the cut had decreased, although some felt that there had been an increase, or there had been no change. Interviews with the antenatal clients revealed that while 70 percent reported having had a type III cut, 26 percent reported a type I cut and four percent a type II cut, suggesting that although cutting is universal, infibulation is not. Most respondents, however, did not know precisely which parts of the female genitalia are actually cut. They used a general term to refer to the clitoris, but which actually encompasses the clitoris, the prepuce, and at least the labia minora.

As it had proven impossible to find any uncut women or girls to interview, these findings suggest that the practice actually continues to be universal (contrary to the health workers' perception), but that there may be a trend towards a less severe type of cutting. This is supported by the fact that 30 of the 44 health workers thought the procedure was now less painful than it had been in the past ten years, probably because of increased use of local analgesia and increased medicalisation; the remainder felt that there had been no change or it was more painful.

\footnotetext{
23 Gruenbaum E., op cit.
} 
Likewise, 27 health workers thought that health complications as a result of genital cutting had declined, although 11 thought that there had been an increase.

One-quarter of the ANC clients did not want to circumcise their daughters in the future. Of those wanting to continue the practice, only 17 percent wanted their daughters to go through the same type of cut as they had, with 56 percent wanting their daughters to have a type I cut. Almost onequarter (22) of the ANC clients thought that clitoridectomy was the type of cut recommended by Islam, and seven of them thought that it could be performed in health facilities.

\section{Who performs the procedure?}

The vast majority (40 out of 44) of health workers said that traditional practitioners were mostly responsible for performing FGC in the community, although almost half of them also mentioned nurse/midwives, traditional birth attendants, and elderly women in the village; six also mentioned doctors and clinical officers. Among the 100 ANC clients who had been cut, 16 percent said that a health worker had cut them. It is important to note, however, that all except one of these women lived in Nairobi, and thus a trend towards medicalisation of the practice seems to be occurring there, as 15 out of 49 women (31\%) had been cut by a health worker.

Traditional practitioners stated that most of them performed FGC for financial gain, although some also argued that they did it to help the community fulfil a religious requirement. "We do it for the sake of religion for purifying... it is both to maintain our culture and a way of earning respected livelihood." (FGC practitioner, North Eastern Province)

\section{Who makes the decision to circumcise?}

The girl's mother and grandmother appear to have the most influence in deciding whether a girl will be cut. Mothers are considered lifelong guardians of their daughters, and all responsibility for her daughters lies with her as long as she is alive. Male relatives have hardly any influence on whether a girl will be cut or not, or on the type of cut the girl should undergo. "The decision on female circumcision is made by the mother, although the father will be informed, it is the woman's duty to make the decision on when and where the girl will be circumcised." (FGD, old men, Mandera)

However, some women interviewed argued that it is the father who held the most influence because the girl cannot be circumcised without his consent. "The father, other than meeting the cost of FGC, occasionally reminds the mother whether the girls are circumcised. The authority of cutting or not, lies with the father but the mother implements. " (FGC practitioner, North Eastern Province) Thus as head of the family, the father has overall responsibility for determining whether or not a daughter is cut, but it appears that it is the women in the family who organise the cutting itself.

\section{How is the procedure undertaken?}

Virtually all ANC clients reported being cut before their tenth year, and in all cases before thirteen years. A traditional practitioner reported that the youngest age at which she had cut a girl was thirty-two days, and that was her own daughter. FGC is preferred at an early age because the bleeding is minimal, the wound is thought to heal faster, and the younger girls are easier to handle and manage during the process. 
The girl's home was cited by three-quarters of health workers as the most common venue for cutting. Other sites mentioned included another person's home or the traditional practitioner's home, although health facilities were cited by five of the health workers interviewed in Nairobi. Choice of location is based on several factors: the need for privacy; ease of managing the girl; and whether the location is culturally acceptable to the family.

There is usually no ceremony around the cutting, and the girls may be cut alone. Sometimes girls of the same age, who may be related or live in the same neighbourhood, may be cut in groups at one girl's home (among the ANC clients, 68\% were circumcised in a group). At no time, however, are girls cut in public in the Somali community. There are no ceremonies, rituals, or orientation for adulthood that accompany or provide the framework for the cutting. Occasionally tea parties will be organized by the mothers to offer prayers for the girls. Unlike other communities, FGC has no role as a preparation for marriage, rite of passage, or a transition to adulthood.

Whether in a group or alone, there are usually about four women present at the cutting, two to hold each of the girl's legs apart, one to hold the head and hands, and one to do the cutting.

We first cut the clitoris from its base, then the sides, the black feather like part which comes down is cut up to its bottom and the sides which does not have the black feather is scratched with a bent blade on both sides and virtually remove every thing between the legs and the edges are brought together and then smeared with a paste locally called malmal. These days we stitch, but [for a] long time we used acacia thorns for stitching. (FGC practitioner, North Eastern Province)

A girl is usually cut using a razor blade provided by the family, although it is common for girls cut in groups to share the same blade or use a shared traditional knife. Most health providers described the instruments used in performing FGC in health facilities as clean. The girls are not required to bathe, nor is there any cleaning of the genitalia before the procedure. According to a key informant in North Eastern Province, the traditional circumcisers do not wear any protective garments when they perform the procedure: "They do not know what gloves are and use bare hands to cut."

Traditionally, acacia thorns or hairs from a giraffe's tail are used for stitching the raw tissues together. Hospital-trained traditional birth attendants use catgut sutures, which are reportedly bought from chemist shops; medical personnel who perform infibulation also use catgut sutures. Sewing thread, string from sisal sacks, and tree bark were also reported to be used in the rural areas.

An herbal paste (called malmal), or the paste made from mixing egg white with wheat flour, is used to stick the cut tissues together as it is thought to arrest the bleeding. When traditional circumcisers perform FGC, the girl's legs are then tied together, from the feet to the thighs, to immobilise the girls and hasten healing. For the first seven days, the girls remain in isolation and are not allowed to walk, and no one is allowed to attend to them. They are untied after the seventh day, bathed and examined to make sure the opening is closed; if it is not, the procedure will be repeated, during which a hot substance may be used to burn the area and make it raw. After being untied, the girls are made to sit on a hole dug in the house and filled with hot charcoal mixed with medicinal herbs, in order to dry the wound and minimise infection. 
Traditional practitioners in Nairobi charge up to Kshs 1200 (US \$15.50) per procedure, depending on the family's income. "Sometimes we charge 1200, 1100, if somebody does not have 500 [US \$6.50], it depends sometimes free." (FGC practitioner, Nairobi) In North Eastern, the cost can be as little as Kshs 200 (US $\$ 2.50$ ), or occasionally payment is made in kind.

\section{De-infibulation at marriage}

Unlike type I and II cutting, which are one-time procedures, infibulation usually requires a second procedure (and possibly more) that may cause complications, in which the vaginal opening is widened to allow intercourse and delivery (termed de-infibulation). Penetration to widen the vaginal opening by the husband's penis is the preferred mode of de-infibulation for the wedding night. This not only demonstrates virginity for the woman, but also manliness on the part of the man. If tough scars make this difficult, the husband's mother is expected to arrange for the girl's mother, or another elderly woman, to come and cut open the vagina using a knife, razor blade, or scissors. "On the evening of the wedding the girl should be cut for the husband. They use a big blade and it is at the available opening and pulled up as it cuts the stitched skin. Due to the resultant wound, some women would refuse the husband to use the place. If she cannot persevere the pain, she may run away from the husband. Others go secretly to the hospital to be reopened." (Elderly women FGD, Nairobi)

It was also reported that occasionally the man, out of fear of the shame of being considered a weakling if he is not able to open her with his penis, might take a knife and cut the woman himself. Those living in Nairobi reported that they sometimes seek help for de-infibulation from medical practitioners.

\section{Complications of FGC and their management}

\section{Physical complications}

The traditional practitioners interviewed played down complications associated with the practice. Rather than associating them with the cutting procedure or person doing the cutting they said, "[If] some girls get problems due to circumcision, it is God's case. They get problems in passing urine, and during menstrual periods due to blockage." (FGC practitioner, Nairobi) Women reported suffering pain throughout their life as a result of infibulation - during urination, menstruation, de-infibulation, coitus, childbirth, and re-infibulation.

The majority of the health workers interviewed (35 out of 44) said that they had encountered medical complications that they associated with FGC in the course of their medical practice. Problems mentioned included pain (27), bleeding leading to anaemia (26), painful menstruation (25), difficulty in urination (21), scar formation (20), prolonged and/or obstructed labour (21), difficulty with sexual intercourse (21), and perineal tears (20).

Thirty-nine percent of the ANC clients interviewed said that they had suffered some complication at the time of circumcision, and 30 percent of those cut in a group remembered that one of the girls in their group had suffered a complication. The complications encountered ranged from excessive bleeding, occasionally leading to hospitalisation, difficulty in passing urine, pain and shock, to infection and genital swelling.

Because the procedure is normally done without anaesthesia, pain was the most commonly reported complication at the time of cutting. Because pain is considered a normal part of the 
cutting experience, only three of the health workers from Nairobi and six from North Eastern said that they would provide analgesia for pain during the cutting.

Bleeding is also considered normal and, as noted above, various substances are spread on the wound to stop the bleeding. However, "Sometimes this does not help and they either take the girls to health facility if it is near or just wait for nature to take its course into either spontaneous stoppage or death of the girl. They apply some herbs or some tree root." (Elderly woman, North Eastern) Similarly, a women's leader in Mandera commented that, "Bleeding...sometimes may be excessive, so they apply some herbs, or some tree roots are applied on it. Occasionally one will just bleed to death. This death, if it happens, it will be taken to be normal." Another respondent from North Eastern added, "Some women are far away from the hospitals, and only God can assist them so they should just stay at home. Some will die of bleeding."

All groups reported generalised fever and genital swelling after the cutting, sometimes followed by abscess and the formation of cysts. Of the health workers who reported managing girls with FGC-related complications, five in North Eastern and three in Nairobi said that they offered antibiotics to prevent infection.

To treat infections at home, girls are made to sit over hot charcoal. One FGC practitioner narrated her personal experience at circumcision: "They dug some small hole in the ground then put some live charcoal and pulled us to the hole and made us sit on the fire. We screamed that our bottoms were burning and were told to go back to it. I think they were using the fire to kill the bacteria. I think if it were not for the fire we would have died of sepsis." (FGC practitioner, Mandera)

The first time a girl passes urine after circumcision most feel a burning sensation, and because of the fear of this pain they may withhold the urine. A female respondent from North Eastern recounted her experience, "We were tied with rope for the camels from the thighs to the legs and we stayed for seven days tied, we could not pass urine and we were beaten and forced to pass urine." Occasionally during infibulation, the urethra is injured and heals with fibrosis, leading to urinary obstruction or backflow, which causes frequent urinary tract infections.

Almost all the infibulated girls reported suffering dysmenorrhoea (painful menses), probably as a result of the reduced vaginal opening. Menstrual retention can result in infection of both the lower and upper genital tract leading to secondary dysmenorrhoea. "I used to hear a girl in my neighbourhood, usually she is in pain and when I tried to investigate they say that whenever this lady gets her monthly period, she gets pain or kidney problems. She screams and cries. I concluded that she must have got this problem from mutilation." (Opinion leader, North Eastern) One midwife explained that "Menses have nowhere to flow through for everywhere is stitched...so the menstrual blood settles under the skin. The lodged blood gets infected as a culture media and the menses start flowing bacteria into the uterus and causes problem into the uterus, tubes, ovaries..."

Three-quarters of the antenatal clients interviewed reported that they had been afraid of marriage because of anticipated coital difficulties, both in penetration and on de-infibulation; only five percent said that they had been happily looking forward to their wedding night. About one-third experienced difficulty with penetration and 72 percent reported pain and bleeding during penetration. "For the first one, two months, women are confused, in shock, (and) tremble out of 
panic whenever they see the husband for fear of pain inflicted on them due to the raw surface." (Women's leader, North Eastern Province)

Problems at delivery are also common. ${ }^{24}$ A midwife from North Eastern described the problems women may encounter at delivery as follows:

During delivery the child would not be able to pass through the canal due to stitching: the head is not descending and this could be due to the scar of female genital circumcision. After episiotomies because the structures are not normal, she experiences excessive bleeding and may be the child is not expected as required causing fears and other damages or even foetal demise. I have seen two to three percent of those women who deliver in the reserve develop rectovaginal fistula or vesicovaginal fistula.

\section{Psychological and social complications}

About 60 percent of the ANC clients said that they had been given information to prepare them for marriage and the subsequent coital difficulties. This information included that they should expect pain and bleeding, that they must not cry, and that the pain could continue over a long period. Once married, 73 percent of them reported that they were afraid of being married because of fear of sexual penetration, psychological trauma, depression, and lack of sexual satisfaction or desire.

Of the 17 health workers that reported ever managing a woman with social problems associated with FGC, nearly all reported marital conflict, with two citing divorce. This conflict can begin after the wedding night, if the man discovers that the girl had not been "properly" infibulated, or because of failure by the man to penetrate the woman.

About half of the health workers reported encountering clients with psychological complications associated with FGC. The most common psychological complications included fear of sexual penetration, trauma and depression, and lack of sexual desire and satisfaction. Most of the health workers (16) offered advice, while the remainder said that they did not know what to do. When antenatal clients who had undergone cutting were asked about their feelings after they went through FGC, 76 of them were proud, another 15 did not know their feelings, two were indifferent, and two blamed their parents.

\section{Medicalization of FGC}

\section{Involvement of health service providers}

There appears to be an increasing interest among the Somali community for medical staff to perform FGC, especially in Nairobi. Among the health workers, three of the 18 interviewed in North Eastern and 15 of the 26 from Nairobi reported having been approached to perform FGC, and most of them claimed to have been approached more than once. Awareness of the health complications is the main reason. This has been facilitated among those living in Nairobi through exposure to media messages and interactions with other cultures.

Examination of infibulated women during labour is difficult and often the foetus cannot pass through the narrowed orifice unless an episiotomy is given. Obstruction during labour as a result of the tough scar tissue can lead to perineal tears, with subsequent rectal vaginal fistula (RVF) and a weakened anal sphincter. The obstruction can also lead to foetal death or morbidity such as asphyxia or brain damage. 
When the health providers were asked what they would do if they were requested to perform FGC, 12 out of the 18 in North Eastern and nine out of the 26 in Nairobi said that they would counsel the parents against it. However, three in North Eastern and five in Nairobi said that they would carry out the procedure or would refer the parents to a known practitioner. The remainder said they would either turn down the request or report the parents to the authorities. Almost all of the health workers who reported having cut girls said that they used antibiotics and anti-tetanus injections and that the girls went home immediately after the procedure. The families paid about Kshs 500 (US\$ 6.50). The service providers insisted, however, that they were not doing it for the money but to provide a safer service and to prevent medical complications.

There did not seem to be any significant difference in the way the community regarded girls cut by health staff and those cut by the traditional circumciser. This reinforces the observation that FGC is not a rite of passage requiring socially endorsed behaviours, including the use of traditional practitioners. What is important is that the girl is cut prior to puberty - by whom, how, and where are not important.

\section{Role of TBAs in medicalizing FGC}

Training of traditional birth attendants (TBA) to perform safe motherhood functions, both by NGOs and health ministry staff, seems to have contributed to increasing their role in medicalizing FGC in the Somali community. According to most health workers, even if they themselves refuse to perform FGC, the practice will continue through the TBAs, who are often the traditional practitioners as well. A TBA from Mandera said, "I was trained in 1979, I have certificate for TBA. ... I saw it that there were trained health workers and TBAs who could use local anaesthesia, repair the tears and I was one of them. People liked my work and I saw myself assisting people. As time went by I used this practice to supplement my income and it has remained so since then." (FGC practitioner, Mandera)

When the traditional practitioners were asked where they got their medical supplies from, those in Nairobi said that they bought them from the local chemist with no difficulty. These supplies include lignocaine for local anaesthesia, scissors, and antibiotics for infection prevention. "Blades, scissors, everything that is used in the local hospital we buy in the chemist. Local anaesthesia for stopping bleeding, ampicillin if girl gets infection." (Traditional practitioner, Nairobi)

They also said that they had learned how to give injections, and one practitioner from Nairobi reported learning how to use chromic catgut for stitching girls from her training as a TBA. She also used surgical spirits for cleansing the site, a substance not usually used to clean the genitalia.

\section{Antenatal care and birth planning for infibulated women}

\section{Counselling on potential delivery problems}

Of the 57 ANC clients who had delivered previously, only ten had discussed de-infibulation or the potential problems that may occur at delivery during their antenatal consultations. Of these, six had been warned that they might experience problems at delivery, and the other four were told they would be need to be de-infibulated. None had had any discussion about whether they might be re-infibulated after delivery. Moreover, during the current consultation, a similarly low proportion (18\%, and all of these were in Nairobi) of the ANC clients had discussed anticipated delivery problems. 


\section{Re-infibulation after delivery}

It was reported that, following delivery, the nurse or midwife was sometimes requested by the woman to re-stitch her vulva so as to re-create the reduced opening. The main reason given for wanting this re-infibulation was to "make the husband happy" with a small and tight vaginal opening (analogous to the "extra stitch" or "vaginal tuck" sometimes used in Western countries after delivery). Of the 57 ANC clients who had delivered previously, 35 had been re-infibulated, 26 by a nurse or midwife and seven by a TBA (the other two did not specify who did it). Asked if they would seek re-infibulation following their current pregnancy, 35 percent of the women said that they would. Those not wanting re-infibulation mentioned that they wanted a wider vaginal orifice for future deliveries, they feared the re-infibulation procedure itself, and did not want to suffer pain during intercourse.

According to recently married women in Nairobi, it has been common for women to have themselves re-stitched on divorce, even if they have previously given birth. This is seen as an attempt to renew their virginity, thereby improving their chances of remarriage. Given the apparently high prevalence of re-infibulation, greater attention is now being paid to finding out more about the practice, but a recent literature review demonstrated the paucity of scientific data. ${ }^{25}$ Evidence from Sudan suggests, however, that it may be a relatively new phenomenon, practised for the past 60-70 years following exposure to Western practices. ${ }^{26}$

\section{Health facilities' preparedness to handle FGC complications}

To determine the preparedness of the health system serving these communities to manage complications associated with FGC, the resources available and quality of care provided were assessed using an adaptation of the Population Council's Rapid Assessment Tool, originally developed for assessing safe motherhood services with the Kenyan MOH. Two health centres, three hospitals, and three dispensaries in Mandera and Wajir, and six private clinics and nursing homes in Nairobi were surveyed.

The facilities in North Eastern Province had fewer staff in all cadres than Nairobi, including essential staff such as enrolled nurses, laboratory technicians, and medical officers. There were no obstetrician/gynaecologists in the entire province and the few doctors available were only in the district hospitals, which serve as centres of excellence and referral points. One sub-district hospital, El-Wak, had less staff than the minimum required to even run a health centre.

Staff at the health facilities in Nairobi had received updates on essential obstetric care (EOC), whereas in North Eastern Province only two and four staff from Mandera and Wajir district hospitals, respectively, had received any EOC training. Furthermore, no staff in North Eastern Province had received any update training on postabortion care, malaria and anaemia in pregnancy, postpartum and neonatal care, and focused antenatal care. Only one staff member had any training in infection prevention.

Lovel H., N. Bedri, Z. Mohamed, Y. Njikam, R. Moran, C. McGettigan, M. Khaled, M. Magied, and E. Dorkenoo. 2004. "The practice of re-infibulation in the Sudan: Findings from a systematic search of English and Arabic Literature", Paper presented at the Seminar on Advancing Knowledge on Psycho-Sexual Effects of FGCM/C: Assessing the Evidence, INTACT: Cairo. 
Equipment and supplies were also scarcer in North Eastern Province. For example, no facilities had a dressing tray to stop bleeding, and some lacked gloves and gauze. No facilities had a Manual Vacuum Aspiration (MVA) Kit for managing abortion complications, a vacuum extractor for the managing delayed second stage of labour, or oxygen for resuscitation. These shortages mean that these facilities are not able to manage complications associated with FGC, such as bleeding and sepsis, or with obstructed deliveries. Only the two district hospitals had functioning surgical theatres for elective and emergency operations. None of the dispensaries offered normal delivery services though with improved quality of staff they should be able to conduct normal deliveries.

Given the demonstrated relationship between infibulation and an increased likelihood of problems during pregnancy, the capacity of the health facilities to perform the eight 'signal functions' defined by WHO for basic essential obstetric care ${ }^{27}$ was assessed. While all of the facilities in Nairobi could perform all eight functions, none of the dispensaries in Mandera or Wajir could. None of the facilities in Mandera and Wajir could offer MVA or assisted vaginal deliveries, and only the two district hospitals could perform caesarean sections and provide blood transfusion services.

Health information systems were virtually non-existent in almost all facilities, except one facility in Nairobi (Marie Stopes); it was not possible, therefore, to obtain data on the prevalence of obstetric complications. The Marie Stopes clinic reported 22 cases of obstructed labour and six cases of ruptured uterus in 2003, though there was no evidence of a direct link to FGC. None of the facilities had recorded any obstetric fistulae. ${ }^{28}$

\section{Awareness of FGC as a violation of human, legal and sexual rights}

Given that FGC is recognised as a violation of several internationally recognized human rights, was recently criminalized in Kenya, and the $\mathrm{MOH}$ has a policy forbidding its staff from performing FGC, this study sought to document the Somali community's perceptions of women's and children's rights in relation to FGC.

\section{Is FGC seen to violate a woman's human rights?}

In the Islamic religion, the Prophet emphasises that girls have rights equal to boys. Both girls and boys have the right to education, inheritance, shelter, clothing, and food - as well as equal rights to sexual pleasure. Because of this, a key informant in North Eastern noted that "One part of their body is being cut, but they have the right to have their body intact, and they have even the right to enjoy sex or have freedom of what they feel. So I think by cutting them, they are also reducing their rights to enjoy, and also you are causing bodily harm to them." The same person also noted that, "FGC is a human rights issue because the girls are not given a chance to decide for themselves but are forced by their mothers. " (Women's leader, North Eastern) Moreover, a religious leader remarked that "Cutting the girl through FGC and forcing her is violation of her rights and it is against Islam." (Religious leader, North Eastern Province) 
Others interviewed, however, did not regard infibulation, or any form of $\mathrm{FGC}$, to be a violation of the human rights of women and girls. Instead, it was felt that FGC is practised for the benefit of the woman and the girl-child because "[The] female body is like a house and a house needs to be decorated. The FGC is like making a door of a house look better. This is good for both the lady and the man who will marry her. The female body should be strong and resist the male genital penetration with ease." (Female opinion leader, North Eastern)

Some respondents felt that the husband's opinion about FGC was more important than the child's or the mother's, and that the wife had to follow her husband's wishes. "The mother has other rights. When it comes to circumcision she can make a decision on when the child is supposed to be circumcised but a situation where she says [she] must not be circumcised without deciding with the father, I think that is unfair. That will lead to divorce." (Male teacher, North Eastern)

At no time is a Somali girl's consent sought for FGC. When asked whether the child's consent was sought for the procedure, an FGC practitioner replied, "No, nobody asks for her consent. The parents decide for her. They are brought and cut by force." A women's leader noted also that, "The parents consent was what was important, and the girls were forcefully held and cut to the satisfaction of all those present."

These conflicting opinions suggest that, as much as FGC is considered a violation of human rights among the educated and those that are well educated about religion, the majority of Somalis do not view FGC as a human rights violation, but as a service they render to their daughters. An old man from Mandera stated the following, "We know today that infibulation is a violation of the girl's right. We the Somalis never used to see it as a human right issue because it was part of our culture and tradition, and we did not see anything wrong with that practice."

\section{Knowledge of laws regarding FGC}

The majority (84\%) of health providers knew that FGC was illegal in Kenya, but only one-third knew of the Children's Act through which it has been criminalized. When asked about the MOH's National Plan of Action for the Elimination of FGC, only one-fifth of health providers had heard about it, and none of them knew the content, goals, or objectives. Only a few political and opinion leaders in both North Eastern Province and Nairobi knew that FGC was illegal, having heard through the media, but none could remember ever reading an official document about the law. None of the teachers interviewed, either from North Eastern or Nairobi, had heard about the Children's Act or any another law pertaining to FGC. Their only source of information on FGC was from the NGOs active in their areas.

\section{Female sexuality, gender roles and FGC}

A belief commonly expressed was that removal of the clitoris, the scarring, and pain of circumcision are intended to suppress female sexual desire. This was felt to be necessary because "Who expects the lady to enjoy sex? The fact is that the circumcised women do not have any sexual desire and nobody expects her to enjoy sex anyway. ... In the past she was viewed as a slave or sex object. She was supposed to be submissive to the man. It still happens today in some areas." (Older men FGD, North Eastern) "Women are considered like the property of men, an object that can be used by men. Their sexual enjoyment does not matter and they are not meant to show that they enjoy so long as the men are happy." (Women's leader, North Eastern) 
Women are not expected to take the lead in initiating sexual behaviour, as is illustrated by the following quote, in which an older man said, "I have personal experience. At one time I married an Ethiopian woman who was not circumcised, she was hell sexually speaking. Her desire for sex was beyond control. I could not do my other work; she always wanted me to be on top of her. I could not stand this and I divorced her immediately. If she was circumcised and the clitoris removed, she could not have behaved like that." (Older men FGD, Mandera)

Additionally, women are expected to have soft bodies, but the clitoris is viewed as 'hard,' thus removing it is seen to enhance the femininity of the woman's body.

Hardness is associated with men. During the sexual act the male genital hardens, as this is a symbol of strength. If the women are left with a clitoris and it hardens during the sexual act, it will make her equally sexy and aggressive in sex. Then how will the man consider himself? The clitoris, if not cut, will grow long and challenge the penis. The clitoris, if not cut, will give women a male characteristic that poses a challenge to men and no man will like to face that kind of challenge. (Older men FGD, North Eastern)

FGC is considered a way of defining a girl as being female, different to a male, and preparing her to fulfil her role as a woman, a wife, and a mother in Somali society. "Infibulation among the Somalis is meant to some extent to identify the woman's gender." (Older women FGD, North Eastern) An old man from North Eastern added,

The clitoris, for those who are not circumcised, acts as a source of sexual pleasure, and this cutting suppress the desire for sex. In a wider perspective, it can be said that infibulation puts a woman in her place in the community and confirms her status as a woman. Cutting her is to signify her gender and ... the community's protection on her sexuality.... the total removal of the clitoris is traditionally meant to remove the male elements from the women. (Older men FGD, Mandera)

In summary, FGC is seen as a means for ensuring that a woman conforms to the gender norms of neither initiating nor enjoying sex.

\section{Developing an appropriate FGC abandonment strategy}

The feeling was widely expressed that the movement to encourage abandonment of FGC is driven by western interests, with the aim of forcing the Somalis to forsake their traditional culture and become absorbed into a westernised culture. Consequently, future interventions to encourage FGC abandonment in this community will need to ensure the explicit support of political, religious, and other cultural leaders to counter these perceptions. Public education through barazas and community-level group discussions were suggested as appropriate strategies to reach a wide audience. Given the universality of the practice and the strong adherence to the belief that it is an intrinsic cultural behaviour, it was recommended that interventions would be needed with a range of groups within the community.

\section{Religious leaders}

Islamic religious leaders clearly wield much influence in the Somali community because of the strength of belief in following Islamic guidelines on how to behave. Respondents thought, however, that if religious leaders did speak out against the practice and could categorically demonstrate why FGC is neither a requirement nor an option in Islam, then they could convince the public to abandon FGC. "Whatever is said in Islam is what I will abide on. I don't see any 
need of contradicting with religion. If the religious scholars have resolved the issue and say we obey laws, so be it." (FGC practitioner, North Eastern)

Respondents felt that religious scholars needed to explain to the people exactly the Islamic view on FGC. They recommended that religious leaders work in collaboration with health professionals, and that they could use the time during prayers at the mosque to discourage the practice through religious arguments. It was proposed that this could be achieved by initially supporting those religious leaders who believe that FGC is not mandatory to develop ways of communicating such religious arguments during prayer times. They could then organize meetings with other leaders to develop a coherent line of thinking so that all religious leaders give the same messages.

\section{Government leaders}

Most people interviewed felt that the Government had no role to play in relation to FGC because the decision is the responsibility of the girl's parents. It was commonly believed that the Somali community would not obey the national laws forbidding FGC, even if they were aware of them. "If you go to these rural areas and propagate the law, I think one might meet the wrath of the people. People will not accept that. And of course you know it will be very difficult to implement it because you will not be in a house checking or monitoring the movement of every girl in every village." (Male teacher, North Eastern Province)

There were some respondents, however, who suggested that the law needed to be better publicised and that the government needed to be more serious in its implementation. "I don't know if there are any [laws] - I have never heard, and it has never been put in place. I think the government allows circumcision. Otherwise if they are not allowing, then it could not have been happening, and if they have banned then they are not enforcing their rules." (Women's leader, Nairobi)

Political and other leaders indicated that they were willing to advocate against FGC, as long as they themselves had correct information, especially about its adverse effects. They considered themselves to have a vital role in ensuring that government laws are enforced at the community level. Although such leaders could be useful in generating serious discussions about FGC at meetings, it is not clear the extent to which they could motivate community members to abandon the practice. They are, however, in a position to take action against the practitioners, although evidence from other areas of Kenya suggests that this would simply drive the practice underground and increase pressure to medicalise it.

\section{Health care providers}

The majority of the health providers said they would support abandonment of FGC because of the pain and health-related complications associated with it. Two-thirds of providers said that they had ever discussed FGC with their patients, but half of these said that they had difficulties discussing the subject. Health workers are well positioned to influence community practices because they are highly regarded due to their expertise and their close interaction with community members. Given the evidence, however, that several health workers are already involved in re-infibulation, and possibly infibulation, the Ministry of Health will need to first ensure that the workers do not practice FGC themselves before they could be encouraged and supported to argue against the practice. 


\section{Traditional FGC practitioners}

Traditional FGC practitioners continue performing FGC due to the monetary gains received and in response to continued demand for their services. One practitioner said that she had stopped after seeing the complications suffered by circumcised girls and women. Others said that they would abandon the practice if they had an alternative sustainable source of income and if the Government enforced anti-FGC laws. "If the force or law enforcement comes, then nobody will be willing to break the laws. If the government bans our profession, then we have no choice, even if it is important culture." (FGC practitioner, North Eastern)

Whether or not traditional FGC practitioners would abandon the practice if the law were strongly enforced is not clear. There is strong sentiment that FGC is a cultural practice that cannot be governed by civil legislation. Thus, while prosecuting FGC practitioners may reduce their activity, it is unlikely to reduce community support for the practice. Given the experience from other areas in Kenya, it may lead to increased demand for FGC from others, such as medical staff. $^{29}$

\section{Teachers}

Teachers were also considered to be community influentials and could serve as role models if they could be convinced to oppose FGC. Respondents recommended that teachers be trained on the complications of FGC, about the law forbidding it, and about the correct position of Islam. It was also suggested that they be given the power to protect uncut girls in their care, or at least be able to report cases when they know they have happened. Suggestions were also made that FGC needs to be included in the school curriculum so that girls and boys could be sensitised for future decision making when they have their own daughters.

\section{Married women and men}

FGC among the Somali is a behaviour determined and sustained primarily at the family level to ensure social acceptability and status within the community in which its daughters marry. Thus as long as FGC is seen as not only socially acceptable but also as critical for a family to have any status in the Somali community, it is in the interests of both the woman and man in a family to sustain the practice. "They say that if the girl is not circumcised no one will marry her. This is what people believe most. And when there is awareness on circumcision, when it started, people even came to us to complain who will marry our daughters." (Female political leader, North Eastern)

Respondents felt, however, that it would be important to communicate with married women about FGC, in order to initiate contemplation among them about why it would be preferable for them not to cut their daughters in the future. Respondents recommended reaching women through existing women's groups and organisations, and through influential women leaders, so as to take advantage of group dynamics and to build consensus among these groups.

Grandmothers and older women should also be reached with such information, as these women have significant influence at both family and community levels.

Men are recognised as the decision-making head of their households, and as such are a critical audience to reach if the family is to be convinced to abandon FGC. Respondents felt that if the man disagreed with the practice, then the women in his family would also be willing to abandon 
it. However, which arguments could be used to convince the men that their family should stop cutting their daughters remains unknown. Thus, if this strategy is to be followed, it is important to determine exactly what information would be convincing.

It is doubtful that criminalization of the practice is being taken seriously, and evidence from another ethnic group that universally practices FGC (the $\mathrm{AbaGusii}^{30}$ ) has shown that health arguments tend to lead to medicalisation or a reduction in severity rather than abandonment. A recently completed project among Somali refugees in Dadaab ${ }^{31}$ showed that a community-based education campaign did succeed in changing men's attitudes towards cutting by increasing the proportions willing to not cut their daughters in the future. However, the same campaign had no effect at all on the women in the community, and may even have served to reinforce their support for the practice. Consequently, any efforts at community-wide education campaigns would need to take account of the potentially different response to the messages by men and women.

The use of infibulation (as well as lesser forms of cutting) to enforce and prove virginity before marriage clearly emerged as a central reason why the practice continues in a culture that values pre-marital female virginity so highly. While some young men indicated their willingness to marry uncircumcised girls, others were worried that not being circumcised would make it difficult to prove the woman's virginity. One strategy could be to advocate for reducing the emphasis on genital cutting and sewing as the main indicators of virginity, as well as raise awareness of the problems women face if subjected to this form of evidence.

\section{Community development organizations}

Only two organisations were found to be undertaking FGC abandonment activities in Mandera District, and none in Wajir. Habiba International Women and Youth Affairs was creating awareness about the adverse effects of FGC; it has conducted 14 workshops in 12 of the 18 divisions of Mandera district, having trained 720 participants. Women For Peace and Development also has weekly sessions to discourage FGC among its 200 members.

Although there has been strong resistance in the past to organizations implementing FGC abandonment activities in these communities, respondents felt that these organizations have a potential role to play in helping the Somali abandon the practice. They recommended setting up committees of respected community members to work with such organizations in raising public awareness.

\section{Mass media}

Respondents recommended the involvement of the mass media. Posters and radio were recommended as appropriate media, as well as the distribution of cassette-recordings of messages from authoritative religious leaders stating the correct Islamic view on FGC. Also recommended were video shows demonstrating the actual procedure and subsequent complications.

\footnotetext{
$30 \quad$ Njue and Askew, ibid.

31 Chege J., I. Askew, S. Igras, and J. Muteshi. 2004. "Testing the Effectiveness of Integrating CommunityBased Approaches for Encouraging Abandonment of Female Genital Cutting into CARE's Reproductive Health Programs in Ethiopia and Kenya," FRONTIERS Final Report. Washington, DC: Population Council.
} 


\section{Strengthening health services to manage circumcised women}

The health system clearly has a role to play not only in encouraging abandonment of the practice among those seeking services, but also in the management of women who have been cut and infibulated. Despite working among populations where FGC is virtually universal, interviews with staff and visits to health facilities indicated that the health system is extremely unprepared to provide assistance in managing any physical, psychological or sexual problems among women and girls attending the services. This is particularly the case for women attending for antenatal, delivery, or postnatal care, although the situation is exacerbated by the fact that, in Mandera and Wajir in particular, the facilities would be severely inadequate for safe motherhood services regardless of whether the woman had been infibulated or not.

Several activities could be undertaken to strengthen the health sector's response to FGC, and particularly for pregnant infibulated women:

- At the central level, include an orientation on genital cutting during pre-service training to educate nurses and others in identifying the different types of cutting, recognising complications that may be associated with cutting and its management, and understanding the socio-cultural rationales for continuation of the practice.

- Ensure that all health staff are fully conversant with the criminalization of FGC through the Children's Act and with the MOH's policy statements against health workers practising FGC.

- In those districts where it is known that health workers are involved in supporting and/or undertaking genital cutting and re-infibulation, ensure that supervisors at the district level fulfil their responsibility to detect and act against those contravening $\mathrm{MOH}$ policy.

- Build the capacity of health workers to advocate against the practice during routine consultations for primary health care and during community outreach activities.

- For those health providers who work among populations (e.g., the Somali, Borana, Rendile, Maasai) that practice the more severe forms of FGC, thus are more likely to encounter women and girls with associated gynaecological complications, provide training in the medical management of these specific complications. These could include both immediate and long-term complications such as painful and weeping scar tissue and keloids; damaged urethra, perineum, and anal sphincter, including fistula; and greater susceptibility to endogenous and sexually transmitted infections. ${ }^{32}$ Depending on the competence of the provider and the level of the health facility, management may mean referral to another facility or provider.

- For health workers and facilities that attend deliveries among infibulated women, ${ }^{33}$ build their capacity to provide the minimum quality of care needed to handle deliveries that

A study in the Gambia found significantly higher prevalence in biological markers of bacterial vaginosis and herpes simplex virus 2 among women with type II cutting than uncut women (see Morison, L. et al. op cit.), and studies in Burkina Faso (Jones et al. op cit.) and Nigeria (Okonofua et al. op cit.) found significantly higher prevalence of signs and symptoms of reproductive tract infections among cut women.

33 However, only seven percent of pregnant women deliver at a health facility in North Eastern province (KDHS 2003 op cit.). 
may be susceptible to complications associated with infibulation. This could include deinfibulation, correct management of obstructed labour, perineal tears, and postpartum haemorrhage, including episiotomy and caesarean section. It would also include handling birth asphyxia (measured by the Apgar score) and being aware of the increased likelihood of perinatal death.

- These types of complications require not only technically competent staff, but also certain minimum equipment and supplies, such as gloves, caesarean section set, MVA kit, suture tray, antibiotics, analgesics, and blood transfusion services.

- Although only 25 percent of women in North Eastern province receive antenatal care from a health worker ${ }^{34}$ train those nurses providing antenatal care in counselling infibulated women about the likelihood and types of problems that may occur during delivery; strongly encourage her to plan to deliver at a facility to minimise these risks, and advise her to be de-infibulated prior to delivery or during second stage of labour but do not ask for reinfibulation.

- Train and equip providers working among populations that infibulate women to be able to safely provide de-infibulation, ${ }^{35}$ and assist them to offer this service at the time of marriage, during antenatal visits, or during the second stage of labour.

$34 \quad$ KDHS 2003 op cit.

35 Guidelines for undertaking de-infibulation are available, having been developed primarily to meet the demand for such services among migrant populations in more developed countries. 


\section{Conclusions and recommendations}

FGC is a deeply rooted cultural practice among the Somalis that continues without questioning about its origin, purpose, or benefits. Several closely related reasons are used to sustain the practice: religious obligation, family honour, and virginity as a prerequisite for marriage; an aesthetic preference for infibulated genitalia was also mentioned. Unlike several other communities in Kenya, however, FGC plays no role as a rite of passage. Underlying these reasons are the use of infibulation to enforce the cultural value of sexual purity in females, as characterised by virginity at marriage, monogamy during marriage, and an emphasis on male pleasure and female modesty during sexual activity. It is felt that sexually pure women are fulfilling Islamic obligations, are eligible for marriage, and bring honour to their own and their husband's family. Although this rationale reflects the patriarchal and patrilineal nature of Somali society, because FGC determines and reinforces a woman's status in society, the practice is strongly supported by women.

Given the clear strength of feeling by men and women that FGC is a critical component of their culture that they are not yet willing to abandon, efforts to encourage behaviour change cannot focus solely on education about health and rights alone. It will be necessary to tailor these efforts so that the reasons underlying the practice are discussed and debated so that a desire for change emanates from the community itself.

As has been found in other Islamic societies that practice FGC, addressing the belief that FGC is a religious requirement is perhaps the first and most productive way of starting this process. Several arguments can be made to demonstrate it is not an Islamic requirement. These include:

- The practice predated the advent of the Prophet Mohamed (PBUH);

- When the Prophet (PBUH) came, he neither banned nor emphasised it;

- Islamic scholars can easily demonstrate that FGC is not a requirement in the Holy Quran;

- Any injury or death resulting from FGC would oblige compensation according to the Islamic Sharia;

- Many strongly Islamic countries (e.g., Saudi Arabia, Iran, Iraq) have never practised FGC.

Although using these arguments it could be relatively straightforward to argue that infibulation is haraam (forbidden) in Islam, the belief that FGC is Sunna, recommended by the Prophet Mohammed, is harder to dispute. As a result, in Sudan and other countries where this strategy has been used, ${ }^{36}$ a move towards replacing type III with type II or I cutting is happening as communities promote a lesser type of cutting as fulfilment of a Sunna obligation. This study found many indications that the Somalis are willing to abandon infibulation for a lesser type, but how to continue the religious argument that no type of female genital cutting is required, even under a Sunna interpretation of Islamic guidance, will be problematic unless strong statements are made by religious leaders.

The other major rationales are based on norms concerning female sexual purity, thus to address these will require open discussions about sexuality generally, for women and men, so that the possibility of demonstrating sexual purity, both for family honour and for marriage eligibility, can be maintained without genital cutting. Possible strategies revealed by these data include:

36 Gruenbaum E. op cit. 
- Equality in sexual pleasure is a Sunna and can be justified in Islamic texts, and that any form of cutting reduces a woman's right to this pleasure;

- Male sexual pleasure is not enhanced by infibulation, and may actually be reduced because of the physical problems encountered and the pain endured by his wife;

- Men who have experienced sex with uncut women prefer it to sex with cut women;

- Women who have been cut have sexual desires as strong as uncut women, thus cutting a woman does not reduce her sexual urge, as is commonly believed.

Proving virginity at marriage through infibulation is going to be difficult to counter, however, given its straightforward logic. One way to counter this argument may be to generate discussion of the disadvantages of infibulation in terms of not only the many threats to the woman's health, but also to the health of future babies, using the scientific data that are now emerging. This information could then be used in encouraging a consideration of balancing the two perspectives. Widespread public education by respected and well-informed members of the community would be needed to allay fears that only infibulation can prove virginity at marriage and that the health complications are unnecessary risks.

Using arguments that the practice is illegal, or that it infringes upon internationally defined human rights, would seem not to be a convincing strategy with this community. Using these arguments in conjunction with discussions about religious teachings and sexuality may be helpful, however. For example, equality in sexual pleasure can be supported both through reference to Islamic teachings and to international rights.

A key lesson learned elsewhere that would have particular relevance for the Somali community, is the importance of working with inter-marrying groups. A successful approach used in Senega ${ }^{37}$ found that because FGC is a critical prerequisite for marriage, if consensus can be generated that marrying uncut women would be acceptable within the social group (e.g., clan, village), and that this decision is then publicised through a formal declaration by the groups' leaders, then a rapid and irreversible "social convention shift" can happen. ${ }^{38}$ Thus, when developing a strategy for working with community members, it would be important to determine marriage patterns and to organize activities accordingly.

The study found that the health sector is ill equipped to serve women who have been cut, particularly infibulated pregnant women. However, this stems from an overall weakness in the availability and quality of safe motherhood services in North Eastern Province, a situation that exacerbates the risks to mother and baby that may already be increased due to infibulation. In addition, and especially in Nairobi, with greater awareness of possible health complications, health workers are increasingly being approached to perform both initial infibulations and reinfibulations.

Diop, Nafissatou J., Modou Mbacke Faye, Amadou Morea, Jacqueline Cabral, Hélène Benga, Fatou Cissé Babacar Mané, Inge Baumgarten, and Molly Melching. "The Tostan program: Evaluation of a communitybased education program in Senegal," FRONTIERS Final Report. Washington, DC: Population Council.

Mackie, G. 2000. "Female Genital Cutting: The beginning of the end," pp. 253-281, in Shell-Duncan B. and Hernlund Y. (eds), Female "Circumcision" in Africa: Culture, Controversy, and Change, Lynne Rienner Publishers: London. 
A number of specific recommendations were made about the many ways in which the health system could strengthen its handling of FGC among the Somali. Policy makers should seek to improve the management of associated complications within the framework of improving safe motherhood generally, and contribute to abandonment efforts through ensuring that staff adhere to $\mathrm{MOH}$ policy and become involved in community-level discussions to create a climate for behaviour change.

Because of the sensitive nature of the topic and the Somali community's perception that efforts to abandon FGC are driven by international interests that seek to undermine and change their culture, working with the Somali community will require collaboration with credible organisations and individuals that have been active in communities and have gained their trust and acceptance. 